\title{
Editorial
}

\section{Craig Anderson}

The George Institute for Global Health, University of New South Wales, Sydney, NSW, Australia

I am delighted to take over the helm of Cerebrovascular Diseases ("CED") as its editor-in-chief from September 2020. It is a honor to assume this responsibility from Professor Michael Hennerici who had the vision to establish, and sustained energy to maintain, the journal for the past 30 years. Many people have benefitted from his commitment to excellence and scientific enquiry, and in fostering the translation of research into real-life health solutions to improve clinical practice. I look forward to extending this work in steering a journal with high standards of scientific enquiry and communication on the wide-ranging aspects and broad scope of stroke medicine and cerebrovascular disease.

I would also like to take this opportunity to extend my appreciation to members of the Editorial Board and Reviewers, in finding precious time away from competing demands to ensure submitted reports are scientifically valid and have appropriate interpretation and conclusions. I look forward to ongoing mutual sharing of expertise and insights, and in growing the quality and reach of the journal.

Taking on this new role, as with scientific enquiry and learning more broadly, is a welcome distraction during this extraordinary period in history with the COVID-19

karger@karger.com

(c) 2020 S. Karger AG, Basel

www.karger.com/ced

Karger! pandemic. Being in China at the beginning of the year, I saw the crisis rapidly unfold but like most people, did not appreciate the scale and magnitude of what was to occur. The rapid evolution of this crisis from health to economic, and subsequently to social and geopolitical, has been alarming. COVID-19 has not only challenged how we all balance the here and now with the future, but it is also acting as the greater divider within and between societies, with the most vulnerable being the hardest hit.

On a brighter note, though, there are many positive outcomes being realized through the pandemic. International travel restrictions have provided a welcome refreshment to the atmosphere and, together with quarantines and physical distancing, have allowed for more time at home and with family. Many people have been able to work more flexibly and remotely with the aid of technology, and there is an enormous level of cooperation and communication between governments, healthcare professionals, researchers and industry across the globe, all rallying to find effective approaches to diagnosis, prevention, treatment, and management of the virus. It is this desperate need to accelerate such efforts that has prompted changes in the manner in which research is undertaken: ethics and regulatory approvals now have a fast track 
system; there is greater use of remote data collection and monitoring and for wider engagement with patients and the community; and innovative and efficient study designs are being promoted, such as the use of routine data collection systems, registry trials, adaptive designs, and co-enrolment of participants across multiple studies.

Stroke is such an enormous global health problem that cannot be ignored in the context of COVID-19, particularly given the interaction between the virus and comorbid cardiovascular risk factors as well as the need to maintain patients receiving effective time-sensitive treatments to avoid premature death and disability, such as reperfusion for acute ischemic stroke. Yet, like many other disciplines, stroke research and service delivery has been adversely impacted by COVID-19. With the realization that the virus is going to linger for a long time, creativity, cooperation and collaboration, all hallmarks of quality stroke care and research, will feature strongly in seeing us through this period of adversity, disruption, and transition. "A house divided by itself cannot stand" Abraham Lincoln 1858.

Craig Anderson, Sydney, Australia 